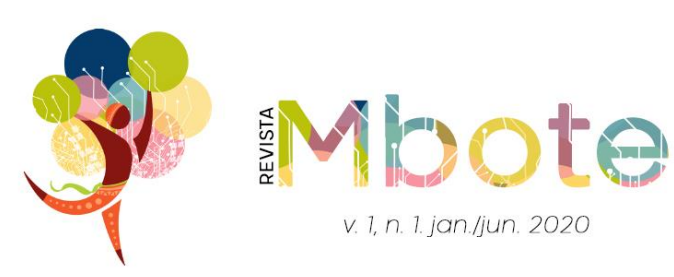

\title{
CIÊNCIA PARA REDUÇÃO DAS DESIGUALDADES: RELATO DE EXPERIÊNCIA DA SEMANA NACIONAL DE CIÊNCIA E TECNOLOGIA DO DISTRITO CRIATIVO DO PELOURINHO
}

\author{
José Cláudio ROCHA ${ }^{1}$; Luiz CARLOS ROCHA ${ }^{2}$; Denise Abigail Britto FREITAS ROCHA ${ }^{3}$
}

Resumo: O presente artigo intitulado Semana Nacional de Ciência, Tecnologia e Inovação do Distrito Criativo do Pelourinho (SNCT Pelô): Ciência para a Redução das Desigualdades é fruto de um estudo de caso, com abordagem de pesquisa-ação, realizado junto a iniciativa de popularização da Ciência, Tecnologia, Inovação (CTI) e Empreendedorismo, do Centro de Referência em Desenvolvimento e Humanidades $(\mathrm{CRDH})$, instituto de pesquisa considerado estratégico pela Universidade do Estado da Bahia (UNEB), através da Resolução CONSU 1247/2016, que tem como principal ação a realização da SNCT Pelô, voltada para um público interativo formado por estudantes da rede de educação básica e profissional; universitários (graduação e pós-graduação); professores (educação básica e superior), ICTS; Empreendedores Econômicos Sociais Solidário e Criativos (EESSC), gestores públicos; profissionais do terceiro setor; e o público em geral. O objeto da SNCT Pelô é justamente popularizar a CTI e o Empreendedorismo, como toda a sociedade baiana e brasileira, considerando essa uma medida essencial na formação de uma cultura de criatividade e inovação em nossa sociedade; empreendedorismo de vanguarda; e fazer da CTI um eixo essencial do desenvolvimento sustentável do país; Diante desse objeto o objetivo geral da iniciativa da SNCT Pelô é popularizar a ciência junto a toda sociedade baiana e brasileira, principalmente, junto ao público alvo do programa nacional da SNCT, priorizando os grupos em situação de maior vulnerabilidade. Nesse sentido, o Distrito Criativo do Pelourinho que fica no Centro Antigo e Histórico de Salvador, se mostra como um centro de convergência dessas discussões, envolvendo grupos e pessoas de nosso estado. Como objetivos específicos estão: participar do esforço acadêmico pela popularização da CTI em nosso país desenvolvido com a SNCT; capacitar o público interativo do CRDH/UNEB voltado para essa questão; difundir temas internacionais; fazer da CTI um eixo para o desenvolvimento sustentável em nosso país. O mundo está em mudança, a sociedade do conhecimento se desenvolve na velocidade imposta pelas Tecnologias de Informação e Comunicação (TIC) e projetos dessa natureza justificam-se pela importância de refletir sobre essas questões, popularizar a ciência com o conjunto da população e fortalecer 0 desenvolvimento sustentável do país. A SNCT Pelô trata de problemas como: ausência de uma cultura e estímulo à CTI em nossa juventude; ausência de uma cultura de inovação em nossas empresas; baixo investimento do setor privado na área da CTI; ausência da cultura de empreendedorismo de vanguarda em nossa juventude; baixa competitividade da indústria e força de trabalho no Brasil em razão da defasagem tecnológica; baixo interesse e proteção à propriedade intelectual; Todos os problemas causados pela dependência tecnológica. A Universidade do Estado da Bahia (UNEB), através da equipe do CRDH, já realiza a SNCT desde o ano de 2007 e dispõe de resultados comprovados quanto a contribuição dessa política para o

\footnotetext{
${ }^{1}$ Pós-Doutor em Direito pela Universidade Federal de Santa Catarina (UFSC). Doutor em Educação pela Universidade Federal da Bahia (UFBA). Professor Titular do Campus XVIII da Universidade do Estado da Bahia (UNEB). Coordenador -Geral do Centro de Referência em Desenvolvimento e Humanidades (CRDH/UNEB). E-mail: joseclaudiorochaadv@gmail.com

${ }^{2}$ Doutor em Educação pela Universidade Federal da Bahia (UFBA). Professor Adjunto do Campus II da Universidade do Estado da Bahia (UNEB). Integrante do Centro de Referência em Desenvolvimento e Humanidades (CRDH/UNEB). E-mail: luizrocha.ba@terra.com.br

${ }^{3}$ Doutora em Educação pela Universidade Federal da Bahia (UFBA). Analista Universitária da Universidade do Estado da Bahia (UNEB). Integrante do Centro de Referência em Desenvolvimento e Humanidades (CRDH/UNEB). E-mail: dfrocha.uneb@gmail.com
} 
avanço do setor da CTI na Bahia e no Brasil. Como resultados poderíamos destacar: Realização de 13 edições da SNCT com público médio de 1.000 pessoas; Produção de dezenas de tecnologias sociais, produtos, serviços, projetos e processo de cunho acadêmico e científico voltados para a inclusão social e produtiva dos grupos atendidos; Capacitação tecnológica de mais de 12.000 pessoas diretamente, atingindo uma rede de mais de 600 mil pessoas em todo país; Produção de dezenas de comunicações de pesquisa sobre a temática da SNCT; Formação de estudantes de doutorado, mestrado, iniciação científica, professores investigadores; entre outros; Fortalecimento institucional dos grupos e movimentos sociais; Ampliar a cultura de CTI na Bahia.

Palavras-chave: SNCT. Ciência e Tecnologia. Inovação. Universidades. Popularização das Ciências.

\section{INTRODUÇÃO}

A Semana Nacional de Ciência e Tecnologia do Distrito Criativo do Pelourinho (SNCT PELÔ) é um projeto de pesquisa, extensão, ensino e inovação social, realizado pelo Centro de Referência em Desenvolvimento e Humanidades (CRDH), centro de pesquisa multiusuário da Universidade do Estado da Bahia (UNEB), através de seus laboratórios e grupos de pesquisa no período de outubro a dezembro de cada ano. A SNCT é uma política pública nacional coordenada pelo Ministério da Ciência, Tecnologia, Inovações e Comunicações (MCTIC), por meio da Coordenação de Popularização das Ciências, como previsto no Decreto Presidencial de 09 de julho de 2004. Tem por objetivo aproximar a ciência e a tecnologia da população, por meio de eventos que congregam instituições de todo o país em torno de atividades de divulgação científica.

Considerando o acesso à Ciência, Tecnologia e Inovação (CTI) como um direito de cidadania e um direito humano, devido a toda sociedade, em tempos de globalização, o CRDH/UNEB promove a SNCT Pelô com o objetivo de promover um ambiente criativo e inovador, propício a popularização da ciência e empreendedorismo, junto a um público interativo formado por estudantes e professores da rede pública de educação básica; professores e estudantes universitários, servidores públicos, imprensa e integrantes de movimentos populares e organizações da sociedade civil. 
Como objetivo específico o projeto traz: ampliar as formas de colaboração entre a pósgraduação e a rede pública de educação básica; promover a CTI como eixo essencial do desenvolvimento sustentável; promover ações que visem a redução das assimetrias inter e intrarregionais (desigualdades regionais); divulgar trabalhos científicos-acadêmicos, assim como novas tecnologias sociais; promover o fortalecimento institucional do empreendedorismo de negros e mulheres na Bahia, como previsto na Lei Estadual 13.208 de 2014.

A metodologia empregada pelo CRDH/UNEB é colaborativa e tem a sociedade como coautora de todo o conhecimento produzido e multiplicadora das ideias, projetos, tecnologias, produtos e serviços divulgados durante a SNCT. A participação da sociedade em todo o processo - da construção a avaliação - é essencial, visto como um imperativo ético. Em termos práticos a SNCT é organizada em múltiplos eventos que ocorrem no período de outubro a dezembro. Esses eventos têm como marca a desmistificação dos códigos científicos e sociais e a utilização de recursos lúdicos, não formais para difundir conhecimento formais relacionados ao campo da CTI. São realizadas atividades como Feiras; Competições de poesia (Slam) e saraus poéticos; música; teatro; cineclube; intervenções fotográficas; gamificação; encontros solidários, com base na ecologia de saberes e na extensão como lócus privilegiado da relação com a sociedade.

Criada inicialmente no município de Camaçari-Bahia, a SNCT passou a ter como centro de convergência de todas as atividades, o Centro Histórico e Antigo de Salvador, particularmente, o Pelourinho, local onde tanto o Governo do Estado da Bahia, assim como, a Prefeitura Municipal de Salvador, têm como proposta trazer para a região projetos de economia criativa. Por este motivo, é que em 2016 a SNCT passou ase chamar SNCT Pelô, atendendo a todo o Território Metropolitano de Salvador, cerca de 16 municípios, incluindo a capital.

O problema econômico-social-cultural-educacional atacado pela ação de realização da SNCT Pelô é a constatação de que a população brasileira, particularmente, a os jovens que estão nas universidade e rede pública de educação básica, têm pouco ou 
nenhum estímulo para o campo da CTI o que, no médio e longo prazos, contribui para uma série problemas estruturantes do país como: ausência de uma cultura de CTI em nossa juventude; ausência de uma cultura de inovação em nossas empresas; baixo investimento do setor privado na área da CTI; ausência da cultura de empreendedorismo de vanguarda em nossa juventude; baixa competitividade da indústria e força de trabalho no Brasil em razão da defasagem tecnológica; baixo interesse e proteção à propriedade intelectual; Todos os problemas causados pela dependência tecnológica.

Nesse aspecto, é preciso despertar na sociedade a importância da CTI para o desenvolvimento nacional e a SNCT cumpre esse papel, estimulando, principalmente, a rede de educação pública a pensar sobre isso. Cada vez mais a distância entre nações ricas e pobres vai estar no conhecimento, e a sociedade brasileira precisa acordar para o fato de que o Brasil não pode continuar sendo, somente, uma nação agrário exportadora.

O CRDH/UNEB foi criado com o intuito de fazer da CTI um eixo fundamental do desenvolvimento sustentável, aplicando o conhecimento na resolução dos grandes desafios nacionais. Sua presença estratégica no Centro de Salvador the permite participar da implantação de um Distrito Criativo no Pelourinho, aproveitando o ambiente propício para desenvolver projetos como a SNCT.

A SNCT Pelô envolve todos os atores na região para discutir formas de tornar a CTI um eixo de desenvolvimento local apoiando as iniciativas de economia solidária, criativa e colaborativa, assim como a formação de novos talentos para setor. A SNCT Pelô 2018 pode ser vista como um circuito de eventos que visa popularizas a ciência e o empreendedorismo, ampliando uma cultura de educação para a CTI em nosso Estado.

A Universidade do Estado da Bahia (UNEB), através da equipe do $\mathrm{CRDH}$, já realiza a SNCT desde 2007 e dispõe de resultados comprovados quanto a contribuição dessa política para o avanço do setor da CTI na Bahia e no Brasil. Como resultados 
poderíamos destacar: Realização de 12 edições da SNCT com público médio de 1.000 pessoas; Produção de dezenas de tecnologias sociais, produtos, serviços, projetos e processo de cunho acadêmico e científico voltados para a inclusão social e produtiva dos grupos atendidos; Capacitação tecnológica de mais de 12.000 pessoas diretamente, atingindo uma rede de mais de 600 mil pessoas em todo país; Produção de dezenas de comunicações de pesquisa sobre a temática da SNCT; Formação de estudantes de doutorado, mestrado, iniciação científica, professores investigadores; entre outros; Fortalecimento institucional dos grupos e movimentos sociais; Ampliar a cultura de CTI na Bahia.

\section{CENTRO DE REFERÊNCIA EM DESENVOLVIMENTO E HUMANIDADES (CRDH), COMO INSTITUIÇÃO DE CIÊNCIA, TECNOLOGIA E INOVAÇÃO (ICT) PROMOTORA DA SNCT PELÔ}

O Centro de Referência em Desenvolvimento e Humanidades (CRDH) da Universidade do Estado da Bahia (UNEB) é a Instituição de Ciência, Tecnologia e Inovação (ICT) promotora da Semana Nacional de Ciência, Tecnologia e Inovação do Distrito Criativo do Pelourinho (SNCT Pelô). O CRDH/UNEB é um centro de pesquisa multiusuário, considerado estratégico pelo CONSU/UNEB através da Resolução 1247/2016, tendo como missão institucional: aplicar o conhecimento científico na resolução de problemas educacionais, econômicos, sociais, culturais e ambientais, fazendo da Ciência, Tecnologia e Inovação (CTI) um eixo fundamental para o Desenvolvimento Sustentável, com respeito à cidadania, à democracia e os direitos humanos, promovendo a indissociabilidade entre ensino, pesquisa, extensão e inovação social.

Em sua visão estratégica, o CRDH/UNEB pretende constituir-se com um Centro de Pesquisa, multiusuário, interdisciplinar, de excelência, estratégico e referência em pesquisa, extensão, ensino e inovação social para a Bahia, o Brasil e o mundo. Os valores de referência para o $\mathrm{CRDH} / \mathrm{UNEB}$ são a ética; respeito à cidadania e a dignidade humana; educação com bem público; indissociabilidade entre Ensino, Pesquisa e extensão; ciência, tecnologia e inovação como eixo fundamental para o 
desenvolvimento sustentável. Seus princípios são: respeito à diversidade, direitos humanos e cultura da paz; respeito ao Estado democrático e de direito; produção e difusão continuada do conhecimento; excelência e qualidade na educação pública; utilização de métodos participativos e colaborativos de pesquisa, extensão, ensino e inovação social; Ecologia de saberes; foco na solução e não no problema; criatividade e Inovação na resolução de problemas da nação.

Do ponto de vista histórico o CRDH/UNEB é o 13ํ (décimo terceiro) centro estratégico de pesquisa criado pela UNEB. O trabalho que dá origem ao Centro tem início em 2006 com a criação do primeiro Grupo de Pesquisa em Gestão Educação e Direitos Humanos (GEDH), também chamado de Grupo de Pesquisa Olhos D'água, uma homenagem a Fazendo Olhos D'água, região onde fica a sede do Departamento de Ciências Humanas e Tecnologias (DCHT), Campus XIX, Camaçari, Triângulo da Lama Preta, na cidade de Camaçari, Bahia. O segundo grupo de pesquisa criado foi o CriaAtivos: criando um novo mundo, foi certificado pela UNEB no CNPQ em 2012, com a introdução da discussão das novas economias: eco criativa; eco colaborativa; eco solidária; eco circular; entre outras.

O CRDH/UNEB atualmente conta com uma plataforma de pesquisa com 10 (dez) laboratórios de pesquisa aplicada, que atendem a cerca de 100 pesquisadores diretamente e uma rede de comunidades científica e de prática com milhares de beneficiários. No Quadro 01 encontramos os laboratórios de pesquisa aplicada que são encontrados na sede do CRDH/UNEB, Ladeira do Carmo, 37, Santo Antônio, Pelourinho.

QUADRO 01 - LABORATÓRIOS DE PESQUISA DO CRDH/UNEB

\begin{tabular}{|l|l|c|}
\hline NUM & \multicolumn{1}{|c|}{ LABORATÓRIOS } & SIGLA \\
\hline 01 & Observatório de Educação em Direitos Humanos & OBEDHUC \\
\hline 02 & Incubadora Tecnológica de Economia Criativa & CriaAtiva S \\
\hline 03 & Portal Mobte e Redes Sociais na Internet & Mbote \\
\hline 04 & Laboratório de Imagem, Memória e Documentação & LIMDO \\
\hline 05 & Laboratório de Áudio e Sonorização & LASO \\
\hline 06 & Memorial da Pesquisa & $\begin{array}{c}\text { Memorial } \\
\text { CRDH }\end{array}$ \\
\hline 07 & Laboratório de Arte Digital & LAD \\
\hline
\end{tabular}




\begin{tabular}{|l|llc|c|}
\hline 08 & Maat Multiteca & HUB Pelô \\
\hline 09 & $\begin{array}{l}\text { Laboratório Interdisciplinar de Formação de } \\
\text { Educadores }\end{array}$ & LIFE \\
\hline 10 & Brinquedoteca & & \\
\hline
\end{tabular}

Quadro 1 - Fonte CRDH/UNEB

$\mathrm{O} \mathrm{CRDH} / \mathrm{UNEB}$ presta assessoria universitária - através de seus laboratórios - tendo como metodologia de trabalho a pesquisa-ação e a Abordagem Baseada em Direitos Humanos (Human Right-Based Approaches - HRBA) atualizadas, por novas metodologias como o design think e o método da tríplice hélice (ETZKOWITZ, 2009), que prevê a universidade na articulação do setor público - universidades - setor produtivo (mercado e $3^{\circ}$ setor). A assessoria universitária é prestada as comunidades de prática como: Encontro Mundial Étnico e Turismo (EMUNDE); Rede Refavela; Mulheres Artesãs de Engomadeira; Cooperativa de Mulheres; Liga de Sambas juninos; carnaval no Pelô; 3o setor Bahia; entre outros.

A SNCT Pelô acaba sendo um importante momento de capacitação para essas redes que, junto com o público de estudantes da graduação básica e tecnológica, acabam tendo na SNCT uma oportunidade de capacitação tecnológica.

\section{A SEMANA NACIONAL DE CIÊNCIA E TECNOLOGIA DO DISTRITO CRIATIVO DO PELOURINHO (SNCT PELÔ)}

O Decreto Presidencial de 09 de junho de 2004 (BRASIL, 2004) instituiu no mesmo ano a Semana Nacional de Ciência e Tecnologia (SNCT) como estratégia de difusão do conhecimento para popularização da Ciência e Tecnologia (C\&T). Na época, o Ministério da Ciência, Tecnologia e Inovação (MCTIC), hoje, Ministério da Ciência, Tecnologia, Inovações e Comunicações (MCTIC) é quem está a cargo dessa missão institucional. A SNCT constitui-se da organização de eventos científicos por todo o país, como a apoio das Instituições de Ciência, Tecnologia e Inovação (ICTs), Estados e Municípios, para a realização de eventos e encontros científicos com a finalidade de popularização da C\&T. 
A SNCT é, portanto, uma política pública nacional coordenada pelo Ministério da Ciência, Tecnologia, Inovações e Comunicações (MCTIC), por meio da Coordenação de Popularização das Ciências, como previsto no Decreto Presidencial de 09 de julho de 2004. Tem por objetivo aproximar a ciência e a tecnologia da população, por meio de eventos que congregam instituições de todo o país em torno de atividades de divulgação científica.

Para a equipe de pesquisadores (as) do CRDH/UNEB o trabalho com a SNCT teve início no ano de 2007, um ano depois da criação do primeiro grupo de pesquisa do CRDH/UNEB, na cidade de Camaçari, Bahia. O quadro 02 apresenta os temas trabalhados pelo $\mathrm{CRDH} / \mathrm{UNEB}$ durante a SNCT, em todos esses anos.

QUADRO 02 - SNCT REALIZADA PELO CRDH/UNEB

\begin{tabular}{|c|c|c|}
\hline SNCT Pelô & 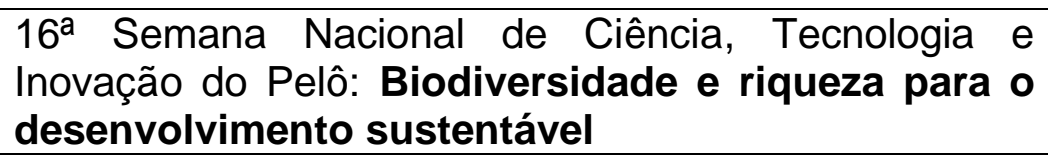 & 2019 \\
\hline SNCT Pelô & $\begin{array}{l}\text { 15a Semana Nacional de Ciência, Tecnologia e } \\
\text { Inovação: Ciência para a redução de desigualdades }\end{array}$ & 2018 \\
\hline SNCT Pelô & $\begin{array}{l}\text { 14 a Semana Nacional de Ćiência, Tecnologia e } \\
\text { Inovação: A matemática está em tudo }\end{array}$ & 2017 \\
\hline SNCT & $\begin{array}{l}\text { 13 a Semana Nacional de Ciência, Tecnologia e } \\
\text { Inovação: A ciência alimentando o Brasil }\end{array}$ & 2016 \\
\hline SNCT Pelô & $\begin{array}{l}\text { 12 } 2^{\mathrm{a}} \text { Semana Nacional de Ciência, Tecnologia e } \\
\text { Inovação: Luz, ciência e vida }\end{array}$ & 2015 \\
\hline $\begin{array}{l}\text { SNCT } \\
\text { Salvador }\end{array}$ & $\begin{array}{l}\text { 11 a Semana Nacional de Ciência, Tecnologia e } \\
\text { Inovação: Ciência, Tecnologia e Inovação para o } \\
\text { desenvolvimento social }\end{array}$ & 2014 \\
\hline $\begin{array}{l}\text { SNCT } \\
\text { Salvador }\end{array}$ & $\begin{array}{l}\text { 10 Semana Nacional de Ciência, Tecnologia e } \\
\text { Inovação: Ciência, Saúde e Esportes }\end{array}$ & 2013 \\
\hline $\begin{array}{l}\text { SNCT } \\
\text { Salvador }\end{array}$ & 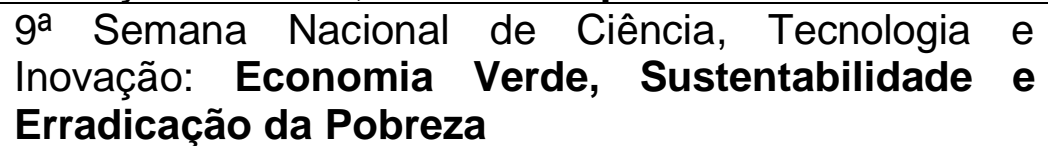 & 2012 \\
\hline $\begin{array}{l}\text { SNCT } \\
\text { Salvador }\end{array}$ & $\begin{array}{l}8^{\text {a }} \text { Semana Nacional de Ciência, Tecnologia e } \\
\text { Inovação: Mudanças Climáticas, desastres naturais } \\
\text { e prevenção de riscos }\end{array}$ & 2011 \\
\hline $\begin{array}{l}\text { SNCT } \\
\text { Salvador }\end{array}$ & $\begin{array}{l}7^{\text {a }} \text { Semana Nacional de Ciência, Tecnologia e } \\
\text { Inovação: Ciência para } \\
\text { sustentável }\end{array}$ & 2010 \\
\hline $\begin{array}{l}\text { SNCTC } \\
\text { Camaçar }\end{array}$ & $\begin{array}{l}\text { 6a Semana Nacional de Ciência e Tecnologia de } \\
\text { Camaçari: Ciência no Brasil }\end{array}$ & 2009 \\
\hline SNCTC & 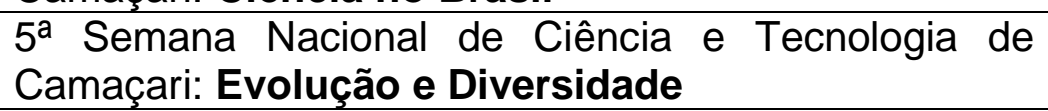 & 2008 \\
\hline
\end{tabular}




\begin{tabular}{|l|l|l|}
\hline SNCTC \\
Camaçari & $\begin{array}{l}4^{\text {a }} \text { Semana Nacional de Ciência e Tecnologia de } \\
\text { Camaçari: Terra - desenvolvimento sustentável e } \\
\text { uso responsável do saber }\end{array}$ & 2007 \\
\hline
\end{tabular}

Quadro 2 - Fonte CRDH/UNEB e Plataforma Lattes

Vale a pena dizer que a SNCT teve uma grande importância na definição do escopo do $\mathrm{CRDH} / \mathrm{UNEB}$, as próprias linhas de pesquisa: desenvolvimento e humanidades foram sendo definidas com base nos temas propostos pela SNCT. Mostra também o envolvimento da equipe de pesquisadores com o desenvolvimento científico.

A SNCT Pelô pode ser definida como um projeto de pesquisa, extensão, ensino e inovação social desenvolvido pelo CRDH/UNEB através de seus laboratórios e grupos de pesquisa no período de outubro a dezembro de cada ano, com apoio das redes de prática e intelectuais. considera o acesso à ciência, tecnologia e inovação, sem esquecer do empreendedorismo, como um direito de cidadania e um direito humano devido a toda sociedade em tempos de globalização, o CRDH/UNEB promove a SNCT com o objetivo de promover um ambiente criativo e inovador, propício a popularização da CTI e Empreendedorismo, junto a um público alvo (interativo) formado por estudantes e professores da rede pública de educação básica; professores e estudantes universitários, servidores públicos, imprensa e integrantes de movimentos populares e organizações da sociedade civil.

Como objetivo específico o projeto traz: ampliar as formas de colaboração entre a pósgraduação e a rede pública de educação básica; promover a CTI como eixo essencial do desenvolvimento sustentável; promover ações que visem a redução das assimetrias inter e intrarregionais (desigualdades regionais); divulgar trabalhos científicos-acadêmicos, assim como novas tecnologias sociais; promover o fortalecimento institucional do empreendedorismo de negros e mulheres na Bahia, como previsto na Lei Estadual 13.208 de 2014 (BAHIA, 2014).

Vale dizer, que SNCT articula-se com políticas públicas fundamentais como: O DECRETO DE 09 DE JUNHO DE 2004 que institui a SNCT sob a responsabilidade do MCTIC (BRASIL, 2004) e as diretrizes para realização da SNCT (MCTIC, 2018); A Lei 13.243 que dispõe sobre o estimula à ciência, tecnologia e inovação e a 
capacitação tecnológica (BRASIL, 2016); A ESTRATÉGIA NACIONAL DE CTI (ENCTI) 2016 a 2019, no que diz respeito a fazer da CTI um eixo fundamental do desenvolvimento sustentável; O PLANO NACIONAL DE PÓS-GRADUAÇÃO (PNPG) 2011 a 2020 (BRASIL, 2010), no que diz respeito a articulação da pós-graduação com a educação básica e redução das assimetrias inter e intra-regionais; O Plano Nacional de Educação em Direitos Humanos (BRASIL, 2009) entre outros documentos de apoio as políticas do $\mathrm{CRDH/UNEB}$. O Pacto Nacional Universitário de respeito à Educação para a Diversidade, Cultura da Paz e Direitos Humanos, parceria com a SECADI/MEC (MEC, 2016); As metas para CTI presentes no Plano Plurianual Participativo da Bahia (BAHIA, 2018).

\section{O DISTRITO CRIATIVO DO PELOURNHO}

O Governo do Estado da Bahia e a Prefeitura Municipal de Salvador têm na Região do Centro Histórico e Antigo de Salvador, como uma região com vocação para a economia criativa, considerando os aspectos culturais e históricos da região. Nessa parte da cidade encontramos os principais equipamentos para a economia criativa, dos mais antigos, casario do Pelourinho, aos mais modernos, Arena Salvador e um novo complexo hoteleiro que se forma no Centro da Cidade. É proposta do Governo do Estado da Bahia, através da Secretaria de Cultura (SECULT) e do Instituto do Patrimônio Artístico e Cultural, destinar cerca de 300 (trezentos) imóveis para a economia criativa fomentando essa política na região.

O Centro Histórico e Antigo do Salvador é uma área que abrange todo Centro Histórico da cidade, composto das áreas do Pelourinho, Sé, Terreiro de Jesus, largo do São Francisco e Santo Antônio além do Carmo, tombada pelo Instituto do Patrimônio Histórico e Artístico Nacional (IPHAN), em 1984, e reconhecido pela Organização das Nações Unidas para a Educação, a Ciência e a Cultura (UNESCO) como Patrimônio da Humanidade, em 1985. Com $0,8 \mathrm{~km}^{2}$, a delimitação do Centro Histórico inicia próximo ao Mosteiro de São Bento e segue até o Forte Santo Antônio Além do Carmo.

Já o Centro Antigo de Salvador é uma área de $7 \mathrm{~km}^{2}$, que inclui em sua extensão territorial 12 (onze) bairros da capital baiana como Centro, Barris, Tororó, Nazaré, 
Saúde, Barbalho, Macaúbas, parte do espigão da Liberdade, Santo Antônio e Comércio, além do Centro Histórico. De com acordo com a legislação, esta área de Salvador corresponde à área contígua à de proteção rigorosa, sob o registro da Lei Municipal $n^{\circ}$ 3.289/83. O Centro Antigo de Salvador é delimitado pela Avenida J.J. Seabra (Baixa dos Sapateiros) até a Região do Campo Grande.

É nessa região que é realizada a SNCT Pelô considerando o Centro Histórico e antigo como um centro de convergência e difusão das tecnologias sociais.

\section{METODOLOGIA E QUESTÃO DE PESQUISA}

A metodologia empregada pelo $C R D H / U N E B$ é a pesquisa-ação como sugerida pelo professor Michel Thiollent (THIOLLENT, 2005), a pesquisa colaborativa (IBIAPINA, 2008), a Abordagem Baseada em Direitos Humanos (Human Right Based Approaches) de Rocha (ROCHA, 2018) e a ecologia de saberes de Santos (SANTOS, 2014). Processo colaborativo tem a sociedade como coautora de todo o conhecimento produzido e multiplicadora das ideias, projetos, tecnologias, produtos e serviços divulgados durante a SNCT.

A participação da sociedade em todo o processo - da construção a avaliação - é essencial, visto como um imperativo ético. Em termos práticos a SNCT é organizada em múltiplos eventos que ocorrem no período de outubro a dezembro. Esses eventos têm como marca a desmistificação dos códigos científicos e sociais e a utilização de recursos lúdicos, não formais para difundir conhecimento formais relacionados ao campo da CTI.

Durante a SNCT são realizadas atividades como: Feiras; Competições de poesia (Slam) e saraus poéticos; música; teatro; cineclube; intervenções fotográficas; gamificação; encontros solidários, com base na ecologia de saberes e na extensão como lócus privilegiado da relação com a sociedade.

O problema econômico-social-cultural-educacional atacado pela ação de realização da SNCT Pelô é a constatação de que a população brasileira, particularmente, a os 
jovens que estão nas universidade e rede pública de educação básica, têm pouco ou nenhum estímulo para o campo da CTI o que, no médio e longo prazos, contribui para uma série problemas estruturantes do país como: ausência de uma cultura de CTI em nossa juventude; ausência de uma cultura de inovação em nossas empresas; baixo investimento do setor privado na área da CTI; ausência da cultura de empreendedorismo de vanguarda em nossa juventude; baixa competitividade da indústria e força de trabalho no Brasil em razão da defasagem tecnológica; baixo interesse e proteção à propriedade intelectual; Todos os problemas causados pela dependência tecnológica.

Nesse aspecto, é preciso despertar na sociedade a importância da CTI para o desenvolvimento nacional e a SNCT cumpre esse papel, estimulando, principalmente, a rede de educação pública a pensar sobre isso. Cada vez mais a distância entre nações ricas e pobres vai estar no conhecimento, e a sociedade brasileira precisa acordar para o fato de que o Brasil não pode continuar sendo, somente, uma nação agrário exportadora.

O CRDH/UNEB foi criado com o intuito de fazer da CTI um eixo fundamental do desenvolvimento sustentável, aplicando o conhecimento na resolução dos grandes desafios nacionais. Sua presença estratégica no Centro de Salvador Ihe permite participar da implantação de um Distrito Criativo no Pelourinho, aproveitando o ambiente propício para desenvolver projetos como a SNCT.

A SNCT Pelô envolve todos os atores na região para discutir formas de tornar a CTI um eixo de desenvolvimento local apoiando as iniciativas de economia solidária, criativa e colaborativa, assim como a formação de novos talentos para setor. A SNCT Pelô 2018 pode ser vista como um circuito de eventos que visa popularizas a ciência e o empreendedorismo, ampliando uma cultura de educação para a CTI em nosso Estado.

A Universidade do Estado da Bahia (UNEB), através da equipe do CRDH, já realiza a SNCT desde 2007 e dispõe de resultados comprovados quanto a contribuição dessa 
política para o avanço do setor da CTI na Bahia e no Brasil. Como resultados poderíamos destacar: Realização de 12 edições da SNCT com público médio de 1.000 pessoas; Produção de dezenas de tecnologias sociais, produtos, serviços, projetos e processo de cunho acadêmico e científico voltados para a inclusão social e produtiva dos grupos atendidos; Capacitação tecnológica de mais de 12.000 pessoas diretamente, atingindo uma rede de mais de 600 mil pessoas em todo país; Produção de dezenas de comunicações de pesquisa sobre a temática da SNCT; Formação de estudantes de doutorado, mestrado, iniciação científica, professores investigadores; entre outros; Fortalecimento institucional dos grupos e movimentos sociais; Ampliar a cultura de CTI na Bahia.

\section{CONCLUSÃO}

Com a emergência da sociedade do conhecimento, a redução da defasagem educacional científica e tecnológica, que ainda separa o Brasil das nações mais desenvolvidas em termos tecnológicos, é uma questão estratégica para o desenvolvimento científico, tecnológico sustentável do país. Nesse sentido consideramos a popularização das ciências com um direito humano e de cidadania de nossa população, principalmente, dos grupos em maior situação de vulnerabilidade social. É uma questão de Estado que está relacionada a própria soberania da Nação brasileira.

Nesse prisma, a política pública da Semana Nacional de Ciência e Tecnologia (SNCT), proposta pelo Decreto Presidencial de 09 de julho de 2004, passa a ter um caráter estratégico na perspectiva da formação de uma cultura de estímulo a Ciência, Tecnologia e Inovação (CTI) junto a toda a sociedade, principalmente, aos jovens estudantes, professores da rede educação básica e universitária, bem como junto aos movimentos sociais organizados. É preciso contribuir para que a sociedade civil organizada (re)conheça a importância de políticas públicas nesse campo e passe a cobrar isso do Estado Brasileiro, envolvendo, inclusive, investimento na educação com um todo. 
A popularização da ciência, meta essencial da SNCT, é uma ferramenta estratégica nesse processo, não há como posicionar o Brasil entre os países mais desenvolvidos em CTI; reduzir as assimetrias inter e intra-regionais; desenvolver soluções criativas e inovadoras para a inclusão social e produtiva; aprimorar as condições institucionais para elevar a produtividade a partir da CTI; ou fortalecer as bases para a promoção do desenvolvimento sustentável, sem que a sociedade como um todo, mas, principalmente, a juventude do país (re)conheça as possibilidades de desenvolvimento nesse campo.

O CRDH/UNEB foi criado com esse intuito, o de fazer da CTI um eixo fundamental do desenvolvimento sustentável, aplicando o conhecimento na resolução dos grandes desafios nacionais. Sua presença estratégica no Centro Histórico e Antigo de Salvador, Ihe permite participar da discussão de implantação de um Distrito Criativo no Pelourinho e realização de uma Semana Nacional de Ciência e Tecnologia nessa região (SNCT Pelô 2018) com o objetivo de produzir e difundir conhecimento sobre CTI aplicada a resolução dos problemas enfrentados por toda a população brasileira.

A SNCT é um projeto realizado pelo grupo de pesquisadores(as) do CRDH/UNEB desde 2007, fazendo do Distrito Criativo do Pelourinho um centro de convergência que recebe pessoas, ideias e tecnologias sociais de todo o Estado da Bahia. A SNCT Pelô envolverá todos os atores na região para discutir formas de tornar a CTI um eixo de desenvolvimento local sustentável apoiando as iniciativas locais de economia solidária, criativa e colaborativa, assim como a formação de novos talentos para setor.

É possível destacar também a importância da SNCT para gerar um ambiente educacional criativo e inovador, capaz de fazer despertar nos diversos atores o interesse por produzir conhecimento e soluções nesse campo, assim como a identificação das redes de prática que atuam nesse segmento. A SNCT Pelô contribui para democratizar o acesso à informação e ao conhecimento, principalmente, aquele relacionado ao campo da CTI; (in) formar um público diverso, amplo e heterogêneo sobre as possibilidades nesse campo e sua relação com as questões da cidadania e dignidade humana; a desmistificação dos códigos científico e tecnológico, realizando 
as atividades em espaços educacionais formais e não formais; bem como estimulando a utilização de recursos didáticos e paradidáticos mais lúdicos na aprendizagem.

Com impacto espera-se também o fortalecimento da política do Distrito Criativo do Pelourinho e a democratização dessa discussão com o envolvimento das redes de prática, como o Fórum de Empreendedorismo de Negros e Mulheres na Bahia (BAHIA, 2014). Promover o acesso e democratização a CTI no Distrito Criativo e em todo o estado é o impacto desejado desse processo.

Ainda como impacto positivo desse processo podemos citar, a partir dos temas propostos para a SNCT, como a ciência pode melhorar a vida das pessoas, melhorar a sua condição humana, fazendo com que as redes gerem conhecimento, empreendedorismo e formulação de políticas públicas, favorecendo o desenvolvimento socioeconômico ambiental. Por fim, destacamos a ampliação do acesso à educação para a CTI como um direito fundamental e humano, com base na Constituição Federal de 1988. Melhorar a cultura de CTI no Distrito Criativo do Pelourinho, na Bahia e no Brasil, produzir e difundir conhecimento nesse campo, estão entre os impactos revelados nesse processo.

O objetivo que cerca a política da SNCT Pelô pode ser enunciado como: Promover ações de popularização da ciência, tecnologia e inovação social, assim como do empreendedorismo solidário de negros, mulheres e pessoas com baixa renda, aplicando o conhecimento científico na resolução dos problemas sociais e desafios nacionais, assim como promovendo a CTI como eixo fundamental do desenvolvimento sustentável.

Esse objetivo geral contempla: as políticas públicas priorizadas pelo CRDH/UNEB descritas na justificativa; a produção e difusão social e coletiva do conhecimento, tendo a educação e a CTI como bem público; A radicalização do acesso ao conhecimento, incluindo, a política de CTI; a articulação de um público amplo, diverso, heterogêneo formado por pessoas que são mais do que sujeitos de uma pesquisa, são protagonistas, coautores de todo o conhecimento produzido e difundido; a 
desmisitifcação de códigos científicos e sociais através da ecologia de saberes (SANTOS, 2011) e da interdisciplinaridade no diálogo entre diferentes saberes (popular e científico). Desmistificar o conhecimento científico é retirá-lo da Universidade (torre de marfim) levando-o para todos os espaços de articulação com a sociedade; utilizar a extensão universitária como lócus privilegiado de produção e difusão de conhecimento articulado com toda a sociedade; Utilizar não só do conhecimento científico, mas de recursos didáticos e lúdicos como saraus poéticos, atividades culturais, batalhas de hip hop, gravação de vídeos e conteúdos digitais, intervenção fotográfica (mobile foto e câmaras digitais), fabricação de jogos; café da manhã solidário (prática da ética da comensalidade).

É importante reconhecer que a sala de aula e processo de educação superior não pode estar restrita a 04 (quatro) paredes, mas é um processo formativo que envolve a realização de atividades em espaços formais e não-formais. Promover a participação e coautoria dos espectadores e participantes em todas as discussões realizadas. Converter conhecimento tácito, fruto da experiência, em conhecimento expresso, materializado nas diferentes formas de preservação do conhecimento científico.

\section{REFERÊNCIAS}

BAHIA, E. D. B. Lei 13.208 de 29 de dezembro de 214 institui o fomento ao empreendedorismo de negros e mulheres PENM. Salvador: LEGISWEB, v. I, 2014.

BRASIL. Decreto 09 de junho de 2004: institui a Semana Nacional de Ciência e Tecnologia. Brasília: Governo Federal, 2004.

ETZKOWITZ, H. Hélice-Triplice: Universidade-Indústria-Governo - Inovação em movimento. Porto Alegre: EDIPUCRS, 2009.

IBIAPINA, M. L. D. M. Pesquisa colaborativa: investigação, formação e produção de conhecimento. Brasília: Liber Livros, 2008.

ROCHA, J. C. Incubação de Empreendimentos Econômicos Solidários no Distrito Criativo do Pelourinho e Território Metropolitano do Estado da Bahia. Universidade do Estado da Bahia - UNEB. Camaçari, p. 10. 2018. 
SANTOS, B. D. S. O direito dos oprimidos. 1. ed. São Paulo: Cortez, 2014.

THIOLLENT, M. Metodologia da pesquisa-ação. 18ª . ed. São Paulo: Cortez, 2005. 